\title{
Self-esteem and social support as predictors of happiness among adolescents living in socio-economic hardship
}

\author{
NEHA SHARMA AND JATINDER KAUR GULATI
}

Received: 21.12.2013; Revised: 17.09.2014; Accepted: 28.09.2014

See end of the paper for authors' affiliations

\section{NEHA SHARMA}

Department of Human

Development, Punjab Agricultural

University, LUDHIANA (PUNJAB)

INDIA

Email: sh.neha.83@gmail.com
ABSTRACT : The present study was investigated to assess the level of happiness among rural adolescents experiencing persistent socio-economic hardship and to examine the contribution of attributes like self-esteem and perceived social support on happiness of rural poor adolescents. The sample included 360 adolescents (15-18 years of age) belonging to intact two parent families and living in conditions of socio-economic hardship. The results revealed that despite of living in conditions of socio-economic hardship, majority of rural adolescents perceived high degree of happiness. Female adolescents perceived significantly more happiness in their life as compared to their male counterparts. Males manifested significantly greater self-esteem than females. Correlation analysis revealed that self-esteem and social support were significantly positively correlated with happiness. Regression analysis revealed that social support emerged as the strongest protective factor.

KEY WORDS: Happiness, Self-esteem, Social support, Stressful life events

- HOW TO CITE THIS PAPER : Sharma, Neha and Gulati, Jatinder Kaur (2014). Self-esteem and social support as predictors of happiness among adolescents living in socio-economic hardship. Asian J. Home Sci., 9 (2) : 402-408. 